\title{
Autologous fascia lata cardiac valve replacement
}

\author{
W. WELCH, P. POT VLIEGE, and G. PRIM O \\ Department of Cardiac Surgery and Department of Pathology, Brugmann University Hospital, \\ University of Brussels Medical School, 1020 Brussels, Belgium
}

\begin{abstract}
During a three-month period, 20 patients had one or more cardiac valves replaced with mounted autologous fascia lata valves. Only six remain alive. Insufficiency of the implanted valve and thromboembolic complications were frequent. Histological examination demonstrates degenerative changes in the fascia lata and explains the thromboembolic phenomena.
\end{abstract}

Prosthetic cardiac valve replacement has been carried out at Brugmann University Hospital since 1962. In a series of 370 valvular replacements, operative and hospital deaths have attained a low rate $(5 \%)$. The overall survival of $70 \%$ is comparable to that of most published series. Late thromboembolic complications, in spite of longterm anticoagulant therapy, remain the principal disadvantage of prosthetic valves. The early success of valvular replacement with autologous fascia lata, as described by Ionescu et al. (1970), prompted us to adopt this technique.

\section{CLINICAL MATERIAL AND OPERATIVE TECHNIQUE}

Twenty patients had deficient cardiac valves replaced with autologous fascia lata during a three-month period from May to July 1970. Thirteen underwent mitral replacement, three aortic, three aortic and mitral, and one mitral and tricuspid replacement. The series comprised 11 women and 9 men, their ages ranging from 32 to 64 years (Table I).

Mounted fascia lata valves were made as described by Ionescu et al. (1970) except that the commissural stitches were not tied over knitted Teflon (Fig. 1). Cardiopulmonary bypass with $5 \%$ dextrose haemodilution and floating temperature was used in all cases. For mitral and tricuspid replacement a row of simple interrupted sutures was used. Figure-of-eight stitches secured aortic valves placed in the subcoronary region. Anticoagulants were not given in the postoperative course.

\section{RESULTS (TABLES I AND II)}

There were no operative deaths after autologous fascia lata valvular replacement. All patients were improved haemodynamically in the immediate postoperative period. Fifteen later showed signs of deterioration of the implanted valve or valves. mitral Valve Replacement Thirteen patients had the mitral valve replaced with fascia lata. Two are at present well, although one developed a slight systolic murmur 11 days after operation.

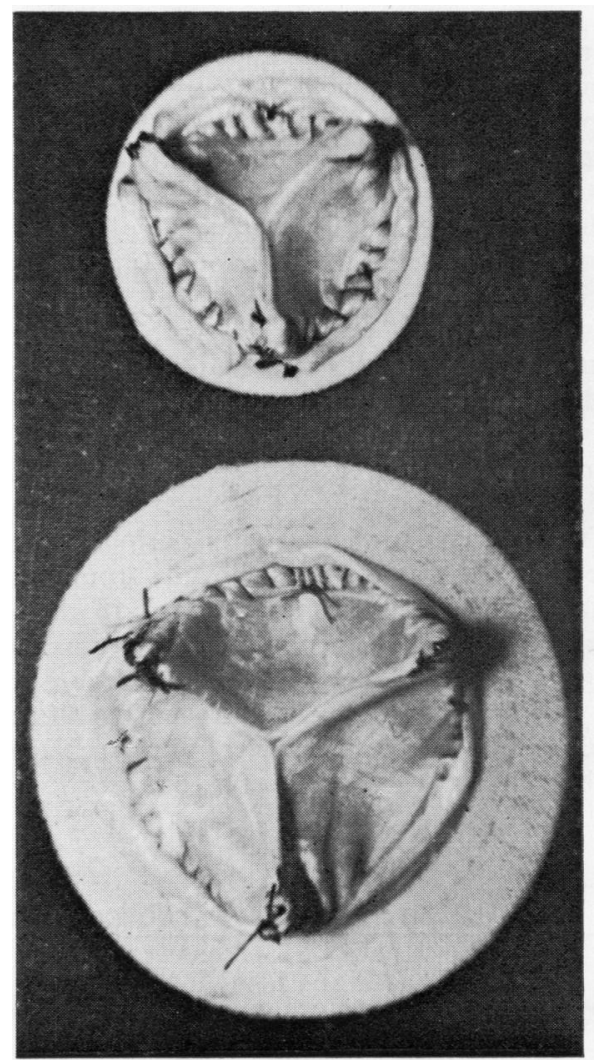

FIG. 1. Fresh aortic autologous fascia lata valve before insertion: top, aortic valve; bottom, mitral valve. 
T A B L E I

AUTOLOGous FASCIA LATA VALVE REPLACEMENTS

\begin{tabular}{|c|c|c|c|c|}
\hline Valve Replacement & No. & $\begin{array}{c}\text { Alive } \\
\text { with } \\
\text { Fascia }\end{array}$ & $\begin{array}{c}\text { Alive } \\
\text { after } \\
\text { Re- } \\
\text { operation }\end{array}$ & Died \\
\hline \multirow[t]{2}{*}{$\begin{array}{l}\text { Mitral } \quad \ldots \\
\text { Aortic } \\
\text { Mitral and aortic } \\
\text { Mitral and tricuspid }\end{array}$} & $\begin{array}{r}13 \\
3 \\
3 \\
1\end{array}$ & $\begin{array}{l}2 \\
2 \\
0 \\
0\end{array}$ & $\begin{array}{l}1 \\
1 \\
0 \\
0\end{array}$ & $\begin{array}{r}10 \\
0 \\
3 \\
1\end{array}$ \\
\hline & 20 & 4 & 2 & 14 \\
\hline
\end{tabular}

T A B LE I I

\begin{tabular}{|c|c|c|c|}
\hline $\begin{array}{c}\text { Cause of } \\
\text { Death }\end{array}$ & & $\begin{array}{c}\text { Valve } \\
\text { Replacement }\end{array}$ & No. \\
\hline $\begin{array}{l}\text { Heart failure due to insufficient } \\
\text { fascia valve } \\
\text { Heart infarct }\end{array}$ & $\begin{array}{l}\ldots \\
\ldots \\
\ldots\end{array}$ & $\begin{array}{l}\text { Mitral } \\
\text { Mitral/Aortic } \\
\text { Mitral } \\
\text { Mitral } \\
\text { Mitral } \\
\text { Mitral/Tricuspid } \\
\text { Mitral }\end{array}$ & $\begin{array}{l}4 \\
3 \\
1 \\
2 \\
1 \\
1 \\
1\end{array}$ \\
\hline
\end{tabular}

${ }^{1}$ Includes patients who died from heart failure after reoperation

Seven others developed severe mitral insufficiency. Two died from heart failure before reoperation was possible. One 50-year-old man developed suppurative mediastinitis on the eighth postoperative day and died 13 days later. However, he had signs of mitral insufficiency 16 days after valvular replacement. Four patients had their fascia lata valve replaced with a Smeloff-Cutter prosthesis when presenting with severe heart failure. Two of these patients died because of low cardiac output after cardiopulmonary bypass. Another died from a heart infarct 17 days after operation. The fourth has been discharged and is well.

Two patients presented with peripheral emboli. One had an embolus removed from the left femoral artery in another hospital 18 days after mitral valve replacement but died from haemorrhage. A 56-year-old woman was readmitted to this hospital for removal of an aortic bifurcation saddle embolus 19 days after mitral replacement. Embolectomy was successful but, although on anticoagulants, the patient died five days later. Necropsy revealed the presence of a massive left atrial thrombus blocking the mitral orifice. Thromboembolic phenomena may have been the cause of sudden death of two other patients of this group.

AORTIC VALVE REPLACEMENT One patient with a fascia lata valve in the subcoronary position developed a diastolic 2/6 grade murmur without cardiac symptoms on the sixth postoperative day and is well three and a half months after operation. Another patient with an aortic implant developed severe aortic insufficiency 28 days after surgery and had his fascia lata valve successfully replaced with a prosthetic valve. The implant which was removed had a commissural tear in one cusp. The third patient with a fascia lata valve in the subcoronary position is well two months after operation.

DOUBLe VALVE REPLACEMENTS All patients who had double valve replacements died. One with an aortic and mitral valve replacement died from liver failure 62 days after operation but had developed mitral insufficiency on the 16th postoperative day. The three remaining patients were reoperated when in severe heart failure due to mitral insufficiency. Two mitral and aortic replacements died immediately after reoperation because of low cardiac output. One patient with mitral and tricuspid autologous grafts died 47 days after reoperation from septicaemia.

Out of 20 patients in this series, six are still alive. Among the survivors are two with an autologous fascia lata valve in the mitral position and two with a similar valve in the subcoronary position. Two patients are well after reoperation, one with a prosthesis in the mitral ring and one with a prosthesis in the aortic position.

All patients with an insufficient valve developed murmurs within a month after operation.

The death rate was highest in patients who had either a single mitral autologous fascia lata replacement or a mitral and another replacement

T A B L E I I I

PATHOLOGICAL FINDINGS (18 VALVES EXAMINED)

\begin{tabular}{|c|c|c|c|c|c|c|c|c|c|c|}
\hline \multirow[b]{2}{*}{$\begin{array}{c}\text { Fascia Lata } \\
\text { Valves }\end{array}$} & \multirow[b]{2}{*}{ Insufficiency } & \multirow[b]{2}{*}{ Stenosis } & \multirow[b]{2}{*}{ Thickening } & \multirow[b]{2}{*}{ Retraction } & \multirow[b]{2}{*}{ Perforation } & \multirow[b]{2}{*}{ Tear } & \multicolumn{2}{|c|}{ Thrombosis } & \multirow{2}{*}{$\begin{array}{c}\text { Degeneration } \\
\text { Fascia Lata }\end{array}$} & \multirow{2}{*}{$\begin{array}{c}\text { Subactive } \\
\text { Bacterial } \\
\text { Endocarditis }\end{array}$} \\
\hline & & & & & & & $\begin{array}{l}\text { Macro- } \\
\text { scopic }\end{array}$ & $\begin{array}{l}\text { Micro- } \\
\text { scopic }\end{array}$ & & \\
\hline $\begin{array}{l}\text { Mitral (13) } \\
\text { Aortic (4) } \\
\text { Tricuspid (1) }\end{array}$ & $\begin{array}{r}12 \\
3 \\
1\end{array}$ & $\begin{array}{l}1 \\
0 \\
1\end{array}$ & $\begin{array}{r}12 \\
4 \\
1\end{array}$ & $\begin{array}{r}10 \\
2 \\
1\end{array}$ & $\begin{array}{r}10 \\
0 \\
0\end{array}$ & $\begin{array}{l}0 \\
1 \\
0\end{array}$ & $\begin{array}{l}6 \\
0 \\
1\end{array}$ & $\begin{array}{r}13 \\
4 \\
1\end{array}$ & $\begin{array}{r}13 \\
4 \\
1\end{array}$ & $\begin{array}{l}4 \\
1 \\
0\end{array}$ \\
\hline
\end{tabular}



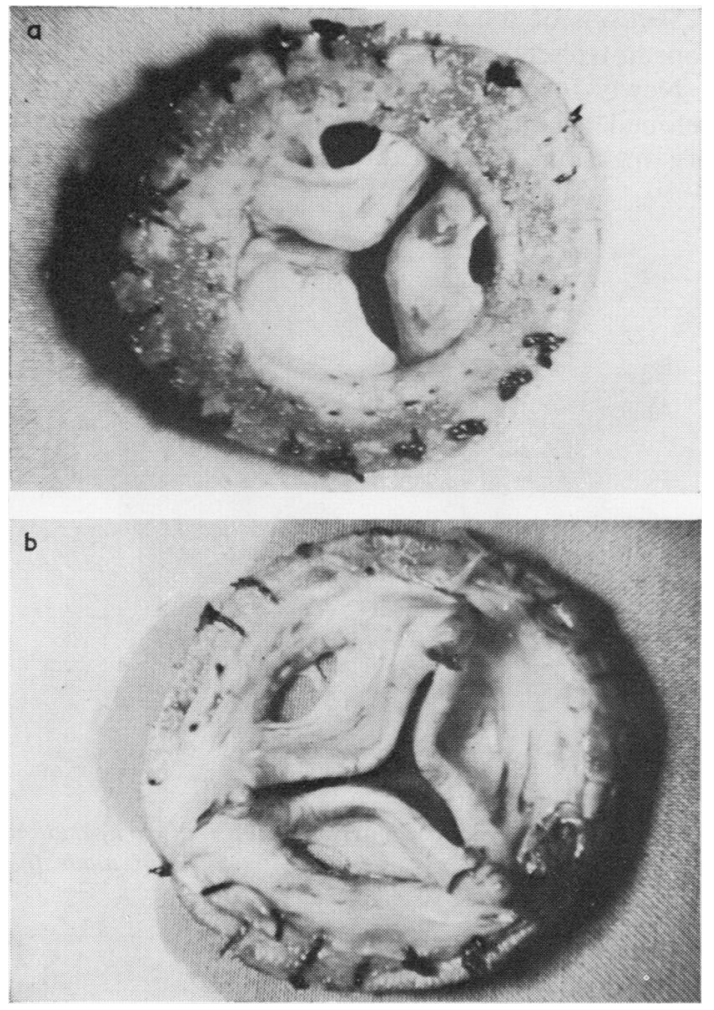

FIG. 2. Mitral valve removed 90 days after operation: (a) atrial aspect; (b) ventricular aspect. Cusps are thickened and retracted and two are perforated.

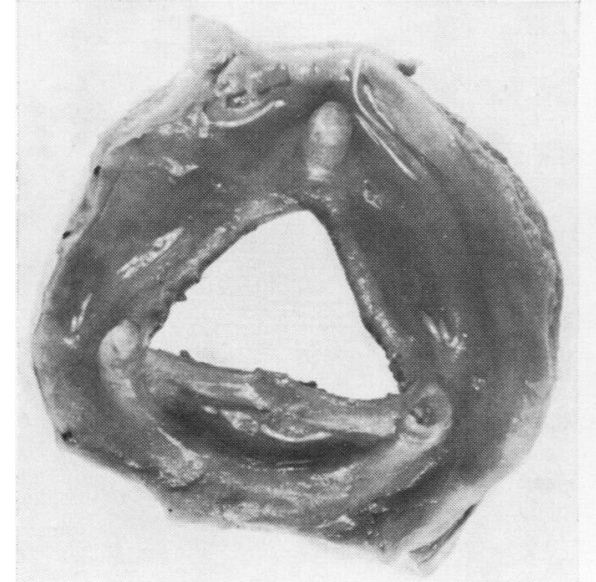

FIG. 3. Mitral valve removed 70 days after operation. Ventricular aspect. Gross retraction rendered the valve insufficient.

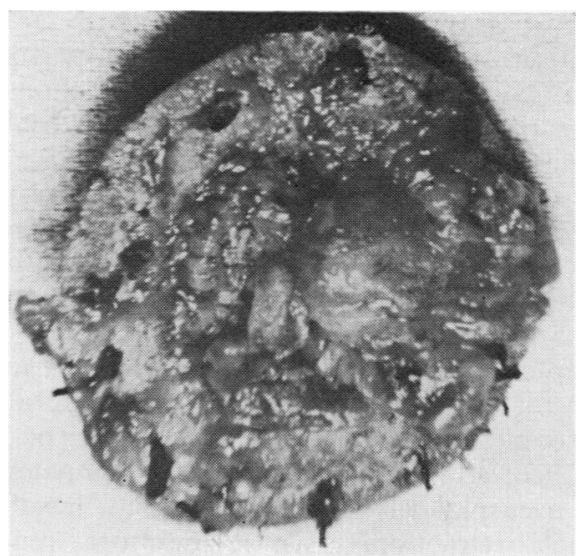

FIG. 4. Mitral valve removed 51 days after operation: top, atrial aspect; bottom, ventricular aspect. There is abundant thrombotic material on both aspects of the valve.

Heart failure from mitral insufficiency caused death or led to reoperation in nine patients. Characteristic in all these cases was the rapid deterioration of the cardiac status, manageable mitral insufficiency reversing into untreatable heart failure within 24 hours.

\section{PATHOLOGY (TABLE III)}

MACROSCOPIC PATHOLOGICAL FINDINGS The fascia lata was thickened in each of the 18 valves examined after reoperation or at necropsy. None leaked around the suture line and tissue ingrowth into the Dacron ring was good.

Ten out of 13 mitral valves had one or more perforated cusps. The perforation was situated in 
the most convex part of the cusp (Fig. 2). Cusp retraction was common even in non-perforated valves (Fig. 3). Five valves with perforations had important thrombotic deposits on both atrial and ventricular aspects (Fig. 4). Two cusps of a mitral valve which was apparently functioning properly were partly fused, thrombus was present on the atrial aspect of these cusps, and a large clot blocking the mitral orifice was present in the atrium (Fig. 5).

Retraction of the cusps was the cause of insufficiency of two aortic valves. A commissural tear was found in a third valve. The last aortic valve examined, although thickened, was competent.

A tricuspid valvular replacement, insufficient through retraction, was furthermore rendered stenotic by the presence of a thrombus moulding the ventricular aspect of one cusp.

MICROSCOPICAL FINDINGS The core of the fascia lata is composed of straight parallel bundles of dense collagen, separated by rows of fibrocytes. One face is covered by a layer of more loosely knit connective tissue supporting some thin-walled blood vessels. The entire thickness of the fibrous membrane is approximately $0.4 \mathrm{~mm}$ (Fig. 6).
Sections of the valves at our disposal show four constant phenomena.

Newly formed connective tissue is variously developed and results apparently from the fibrous organization of fibrin deposits. The longer the

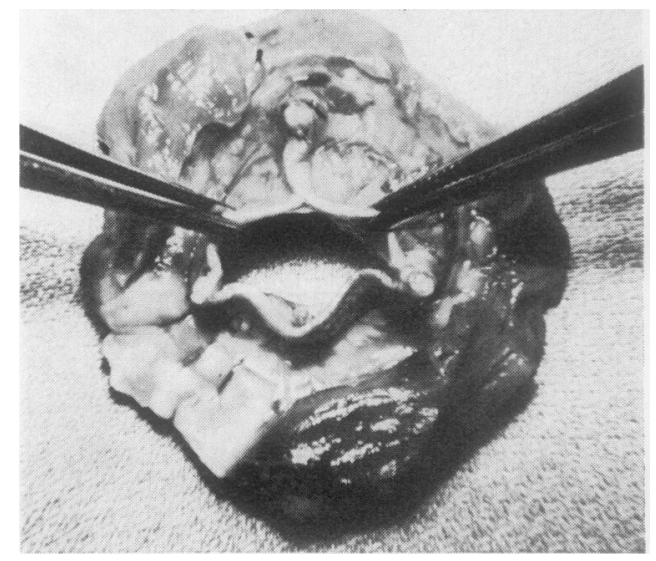

FIG. 5. Mitral valve removed 24 days after operation. Ventricular aspect. Partial fusion of two cusps made this valve stenotic.

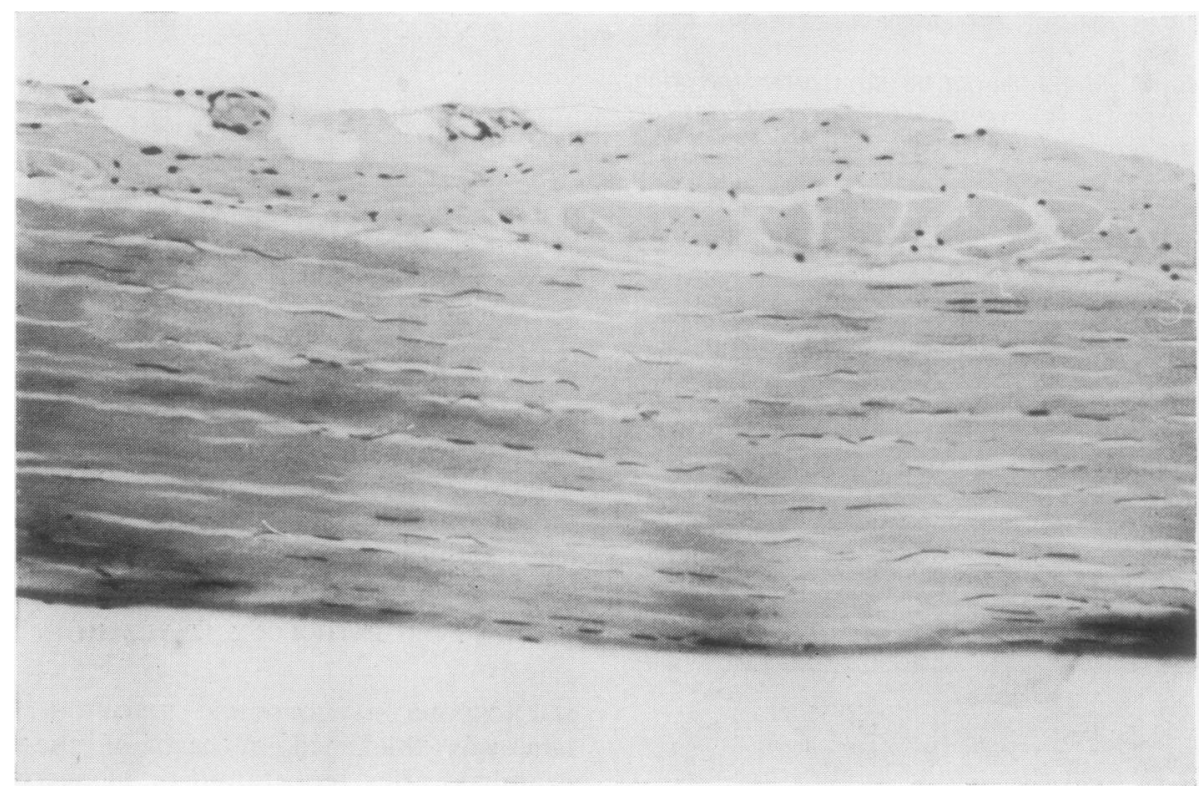

FIG. 6. Longitudinal section of normal fascia lata. The core of the fascia is composed of straight parallel bundles of dense collagen, separated by rows of fibrocytes. One face is covered by a layer of more loosely knit connective tissue supporting some thin-walled blood vessels. The entire thickness of the fibrous membrane is approximately $0.4 \mathrm{~mm}$. (haematoxylin, erythrosin and safranine $\times 140$.) 


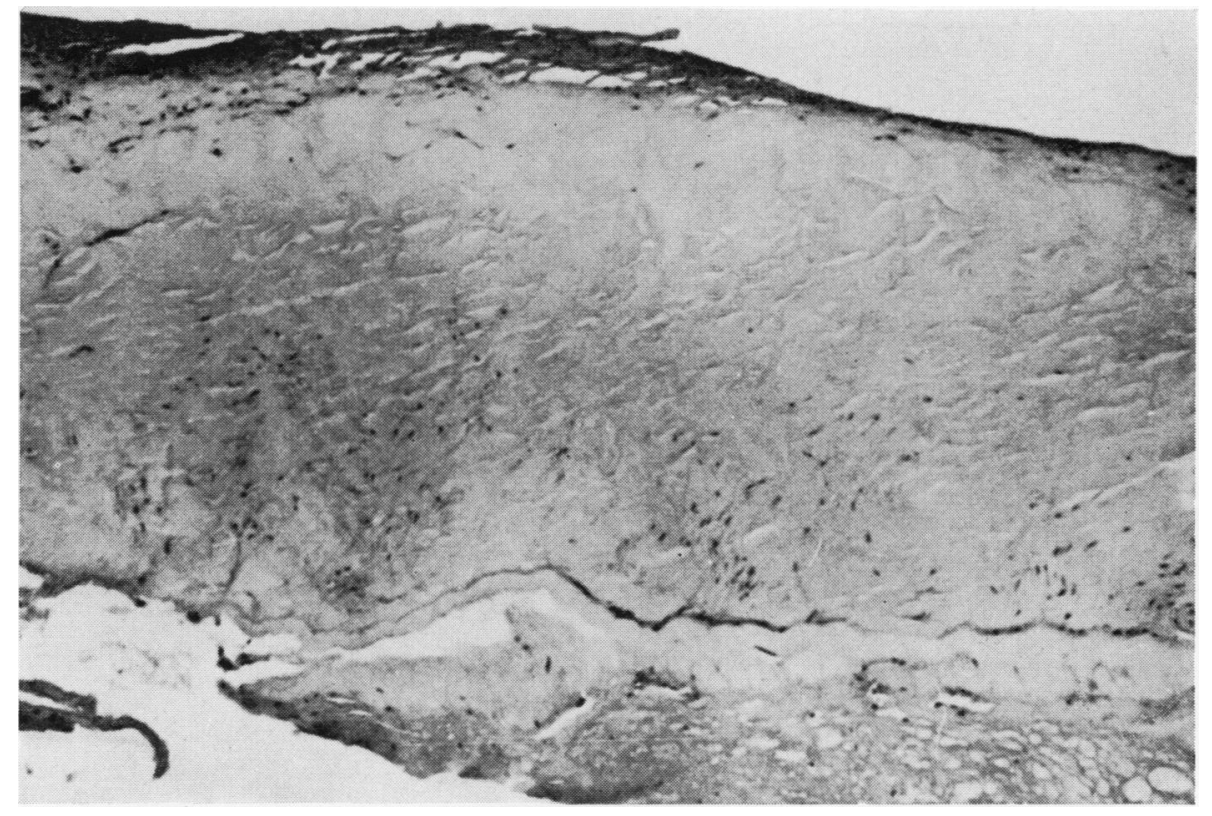

FIG. 7. Tricuspid valve; graft removed 52 days after operation. The coarse collagen bundles of the approximately $0.6 \mathrm{~mm}$ thick fascia lata have become wavy and have lost their parallel arrangement; most of the fibrocytes have disappeared; one face of the graft is covered by fresh fibrin deposits (haematoxylin, erythrosin, and safranine $\times 90$ ).

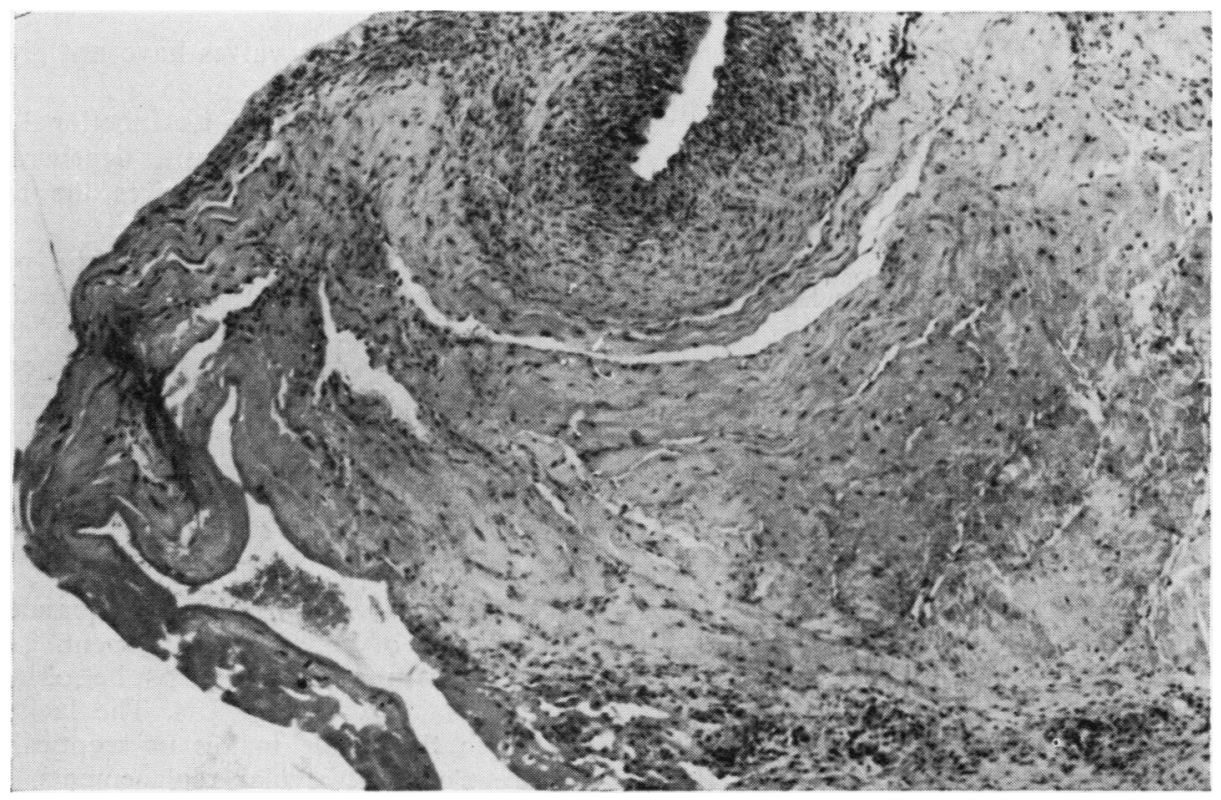

FIG. 8. Mitral valve; graft removed 39 days after operation. Edge of a perforation. The fascia has partially lost its lamellar structure; it progressively becomes attenuated and transformed into an amorphous degenerated material which merges with fibrin deposits on the edge of the perforation. Intact layers of newly formed richly cellular connective tissue are visible on both faces of the central core of fascia lata (haematoxylin, erythrosin, and safranine $\times 55$ ). 


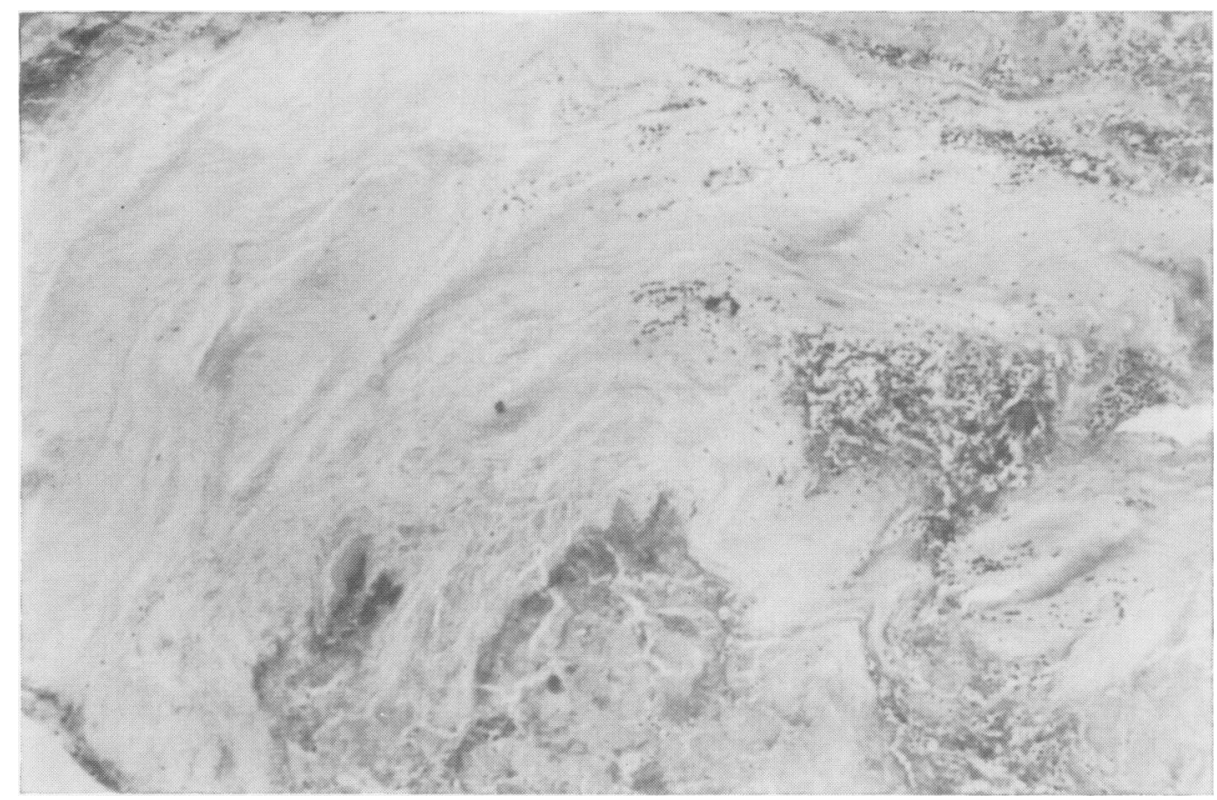

FIG. 9. Mitral valve; graft removed after 90 days. Area of degenerated fascia lata in the vicinity of a perforation. Fibrocytes have totally disappeared; the collagen bundles have become disorganized and are studded with foci of fibrinoid degeneration, some of which are invaded by polymorphonuclears (haematoxylin, erythrosin, and safranine $\times 90$ ).

valve has been in the patient, the more the encasing tissue is collagenized.

In certain places the fascia lata loses its fibrocytes and is composed solely of intercellular material which is not disorganized.

In no circumstances is cellular colonization of the fascia lata found.

Elastic tissue is absent in fascia lata valves (Fig. 7). A lack of elastic fibres was obvious in sections of fresh fascia lata.

In some cases, small remnants of adipose tissue on the surface of the cusps might have favoured the release of thromboplastic substances.

In every perforated cusp, degeneration of the fascia lata appears in the vicinity of perforations. Amorphous deposits of collagen containing red blood cells are dispersed in the normal structure. This may result from the penetration of blood into the fascia lata. Around the perforations the amorphous collagen blends with fibrin deposits (Fig. 8).

A suppurative process with polymorphonuclear infiltrates on the surface of the fascia lata and in the thrombotic deposits was found in four mitral valves and one aortic valve (Fig. 9). Culture of these valves yielded a growth of Staphylococcus albus in two cases.

\section{DISCUSSION}

Mounted fascia lata valves have not given us the results hoped for.

Far from maintaining its functional structure, fascia lata presents necrosis, degeneration, and perforations but never acquires the appearance of a valve.

This type of valve appears to be particularly liable to complications in the mitral position.

The constant occurrence of thrombotic phenomena in our material is an unequivocable fact. Although the deposits on the cusps are in some cases thin and discontinuous, their presence gives an explanation of the severe thromboembolic complications seen in two of our patients.

Fascia lata valves are prone to infection even from Staph. albus.

These considerations led us to abandon the use of this type of valvular replacement.

Better results may perhaps be obtained with free fascia lata valve grafts. The lack of elastic fibres in this tissue makes us sceptical as to its future place in valvular replacements.

\section{REFERENCE}

Ionescu, M. I., Ross, D. N., Deac, R., Grimshaw, V. A., Taylor, S. H., Whitaker, W., and Wooler, G. H. (1970). Autologous fascia lata for heart valve replacement. Thorax, 25, 46. 